\title{
Improving machinability of additively manufactured components with selectively weakened material
}

\author{
Clemens Maucher $^{1} \cdot$ Heiko Teich ${ }^{1} \cdot$ Hans-Christian Möhring ${ }^{1}$
}

Received: 18 August 2020 / Accepted: 18 February 2021 / Published online: 2 March 2021

(c) The Author(s) 2021

\begin{abstract}
Part design and the possibilities of production are disrupted by the increased usage of additive manufacturing (AM). Featuring excellent creative freedom due to the layer-by-layer buildup of components, AM leads to profound changes in future part design and enables previously impossible geometries. Laser powder bed fusion (LPBF) technology already allows to manufacture small quantities of parts with high productivity and material efficiency. Due to the specific process characteristics, the resulting surface finish of these parts is insufficient for a wide range of applications, and post-processing is usually unavoidable. Specifically for functional surfaces, this post-processing is often done by machining processes, which can pose challenges for intricate and complex AM parts due to excessive machining forces. In the present paper, the influence and the possibilities of the LPBF process parameters on the subtractive post-processing are shown. A novel weakened structure is developed to selectively reduce the strength of the material and improve the cutting conditions. Chip formation, cutting forces and vibrations during drilling as well as cutting forces during an orthogonal cut are examined. To quantify the differences, a comparison of the machinability between bulk material, standard support structures and the weakened structure is carried out.
\end{abstract}

Keywords Additive manufacturing $\cdot$ LPBF process $\cdot$ Post-processing $\cdot$ Support structures $\cdot$ Drilling

\section{Introduction}

Additive manufacturing (AM) technologies offer highly complex, individually adaptable geometries to be manufactured, that cannot be produced by conventional methods [1-4]. This is made possible by the additive nature of the processes, that build up parts layer by layer to achieve the desired three-dimensional (3D) shape [5]. The laser powder bed fusion (LPBF) process, as used for this research, utilizes lasers to selectively heat and melt powder to build up these layers. To dissipate heat and avoid thermally induced deformations, support structures are needed on overhanging surfaces [6].

According to Hashimoto there are three key factors to yield the desired functional performance of a mechanical component: material, product design and manufacturing process [7]. A major deficit of the AM processes is the limited resulting surface quality and dimensional accuracy.

Clemens Maucher

clemens.maucher@ifw.uni-stuttgart.de

1 Institute for Machine Tools, University of Stuttgart, Holzgartenstrasse 17, 70174 Stuttgart, Germany
Functional surfaces have to be machined to be within the desired tolerances [8-13]. Additionally, support structures on overhanging surfaces have to be mechanically removed from the part. Subtractive machining processes with a defined cutting edge are used in particular for post-processing $[14,15]$. This is currently done based on experiences gathered from decades of conventional, subtractive manufacturing methods [15-17]. Additively produced parts are mostly treated as raw feedstock with complex geometries, although the additive process can be used for more complex considerations in order to adapt and improve the overall efficiency of the process chain and the manufactured parts themselves.

To leverage the possibilities of the LPBF process, the properties of the resulting components, the quality characteristics within the individual manufacturing steps, and the interaction of successive machining processes must be taken into account. This interaction is particularly important for horizontal bores with increased surface quality requirements. Hintze et al. investigated the effects of helical milling on regular support structures, resulting in reduced but highly fluctuating process forces and increased surface roughness [18]. The entire process chain for the production 
of additive-subtractive components and compliance with the required shape/position tolerances, surface roughness and edge zone properties, is therefore relatively complex.

In order to improve the material efficiency of the overall process and to reduce machining volume a novel developed weakened and porous material which will function as a support structure will be investigated. To achieve this, the LPBF process parameters are used to adapt the geometry and material. This paper offers methods and solutions for an increase in productivity due to lower cutting forces and reduced cutting volume as well as an improved chip removal during the reworking of additively produced bores.

Porosity itself has been widely investigated during development of the LPBF process, mainly to increase the density of manufactured parts and reduce porosity [19]. This was done in order to produce comparable characteristics to conventionally manufactured components. Some researchers have also investigated the LPBF process capabilities with the specific goal to create porous structures for various purposes. One well known application is the usage of porous materials in the medical sector, particularly for implants to improve adhesion to human tissue [20-22]. Porosity has also been examined by Spierings et al. regarding specific material characteristics, such as elasticity and hardness to design functionally improved parts with locally different material properties [23].

\section{Experimental setup}

Samples are additively manufactured, either with a fully dense or the newly developed weakened structure and machined afterwards. Two distinct machining setups are used to evaluate the performance of the weakened structure in comparison to the fully dense material: an orthogonal cutting process to evaluate the weakened structure under the most basic cutting conditions, and a drilling process to serve as a potential application for the developed weakened structures.

\subsection{Additive manufacturing}

A LPBF Machine RenAM 500Q from the company Renishaw is used for manufacturing of the specimens. The specimens are made from maraging steel M300, also known as tool steel 1.2709 . For quality assurance, the powder is examined for particle size distribution and it is found that it is within the range of a typical LPBF powder [24] with the following values: $\mathrm{D} 10=24.45 \mu \mathrm{m}, \mathrm{D} 50=35.47 \mu \mathrm{m}$ and $\mathrm{D} 90=47.79 \mu \mathrm{m}$. Renishaw provided settings were used as process parameters for all parts and support structures except for the adapted weakened structure. An excerpt is listed in Table 1.
Table 1 LPBF process parameters used for material 1.2709

\begin{tabular}{ll}
\hline Process parameter & Value \\
\hline Layer thickness & $50 \mu \mathrm{m}$ \\
Particle size range & $25-50 \mu \mathrm{m}$ \\
Laser power border & $150 \mathrm{~W}$ \\
Laser scan speed border & $300 \mathrm{~mm} / \mathrm{s}$ \\
Laser power hatch & $250 \mathrm{~W}$ \\
Laser scan speed hatch & $1000 \mathrm{~mm} / \mathrm{s}$ \\
Atmosphere & Argon \\
\hline
\end{tabular}

\subsection{Weakened structure explanation}

During the LPBF process the typical goal is to achieve fully dense parts. However, it is also possible to improve the cutting conditions during post-processing and reduce cutting forces by utilizing the possibilities of the process. Several options are considered and the selected one is to create a slightly weakened structure by manipulating the LPBF process parameters in order to reduce the material strength. This manipulation is made by lowering the induced energy during the process resulting in a lower density and strength of the material. To achieve this, the distance between the laser tracks, which is typically $75 \mu \mathrm{m}$ for the selected configuration, is increased. This leads to gaps between the current molten metal and the adjacent and solidified laser track. These gaps are partially filled with powder and act as weak spots during the cutting process. The concept of the formation of these structures is illustrated in Fig. 1.

Two versions of this weakened structure are examined (W2 and W3 with a hatch distance of $200 \mu \mathrm{m}$ and $300 \mu \mathrm{m}$ respectively). In Fig. 2 the surfaces of the two versions in comparison to a surface of a fully dense part ( $\rho=8.1$ $\mathrm{g} / \mathrm{cm}$ ) can be seen. The voids lead to a reduced density of $\rho_{W 2}=7.6 \mathrm{~g} / \mathrm{cm}$ and $\rho_{W 3}=7.1 \mathrm{~g} / \mathrm{cm}$. All density values are measured using the Archimedes principle.

\subsection{Specimen design}

The workpiece geometry for the orthogonal cutting investigations is made out of a beam of maraging steel with a length of $180 \mathrm{~mm}$, width of $5 \mathrm{~mm}$ and height of $50 \mathrm{~mm}$. The sample is split into four individual sections with a different density, to directly compare the effects of the weakened structure on cutting forces and chip formation within the same cut. The first and last section, both $35 \mathrm{~mm}$ in length, are made out of fully dense material. The two middle sections, both $55 \mathrm{~mm}$ in length, are made out of the developed weakened structure $\mathrm{W} 3$ and $\mathrm{W} 2$, respectively. Twenty orthogonal cuts are performed on one sample. 
Fig. 1 Principle of the formation of pores or weakened structures in the AM process [25]

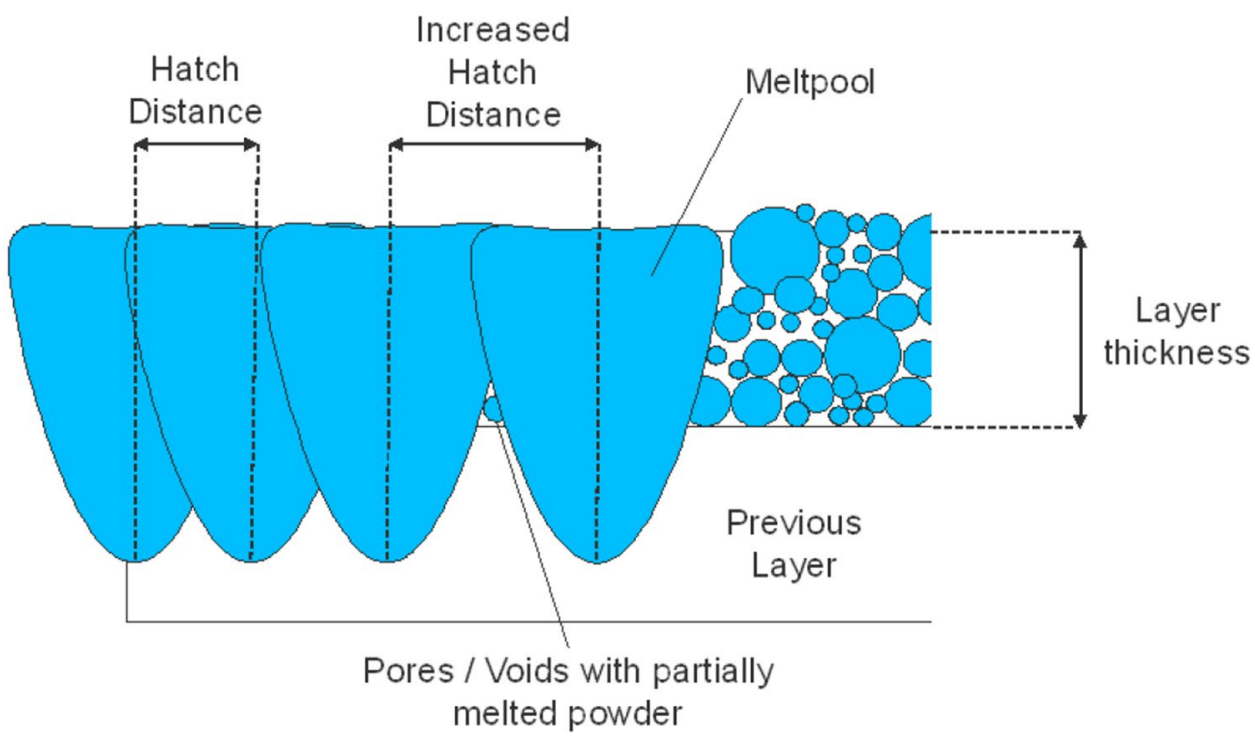

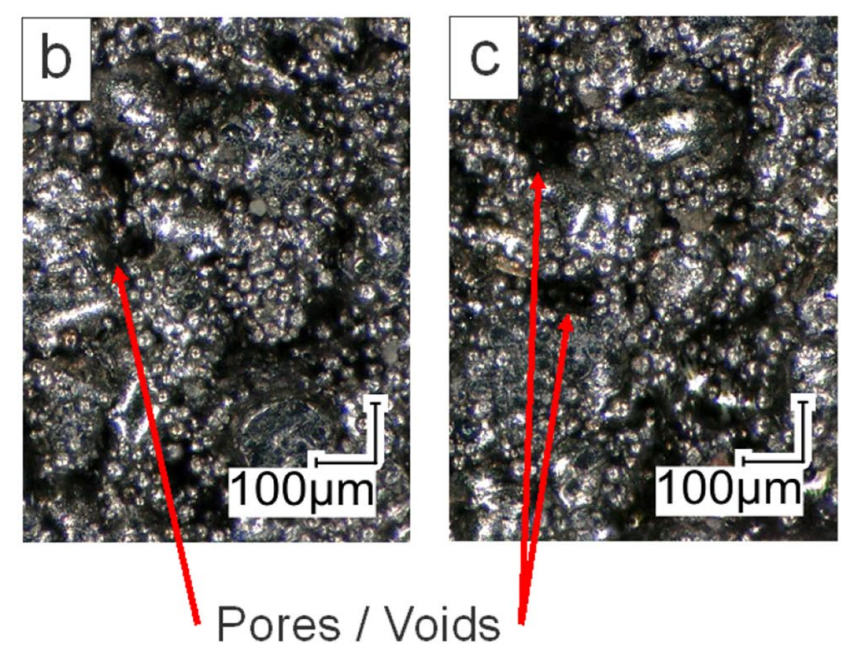

Fig. 2 Surface pictures of the fully dense (a), weakened structure W2 (b) and weakened structure W3 (c)
As an application example and in order to exclude as many influences of the LPBF process on the geometry as possible, the drilling application specimen are designed as horizontal cylinders with the same outer diameter and with a varying central bore geometry. A chamfer is added on one side to aid the tool engagement (diameter of $18 \mathrm{~mm}$ ). The intense heat that is generated by the laser beam to melt the material during the LPBF process has to be dissipated fast enough to not affect the neighboring loose powder or cause the part to locally overheat. This means that every new layer of fused powder has to be supported by the previous layer. Areas where this is not the case are assisted by so-called support structures. They provide a path to dissipate heat and prevent overheating. It is recommended to use supports for all downward facing surfaces with an angle lower than 45 to maintain part quality [5]. To examine the weakened structure, samples are built with a cylindrical region (diameter
$12-5 \mathrm{~mm}$ ) of intentionally weakened material W2 or W3, referred to as "Ring" samples. Due to the reduced energy input, this region can also serve as a support structure of the bore. There are also fully dense "Ring solid" samples built for comparison purposes. Although this is typically not recommended without support structures, it is still possible with a $12 \mathrm{~mm}$ diameter.

To investigate the chip formation and machining forces in comparison to commonly used support structures, specimens with a standard "line" and with a rhombus support structure are produced.

In addition, specimens without a prebuilt bore are produced in fully dense, W2 and W3 variants (up to $14 \mathrm{~mm}$ diameter), and compared with conventionally manufactured maraging steel samples, to assess the impact of the weakened structure on a large cutting volume with high machining forces. Three test specimens are built for each variation. 
The dimensions of the test specimens, the buildup direction during the LPBF process, the different central bore geometries and the proportion of the weakened structures are shown in Fig. 3. Not all produced samples are shown. "Ring solid" samples share the same base geometry as W2 and W3. A photo and section view of the weakened samples can be found in Fig. 4.

\subsection{Machining}

The orthogonal cutting is performed on a special test stand that enables relative linear movement between the sample and the tool (see Fig. 5). The workpiece holder is driven by a linear motor while the tool holder is stationary during the cutting process. The tool holder height can be precisely adjusted to set the depth of cut. Samples are clamped on a dynamometer type 9263 by Kistler, in order to measure the resultant process forces: cutting force $F_{x}$ and thrust force $F_{z}$. In addition, a structure-borne noise sensor using High Frequency Impulse Measuring (HFIM) is placed on the tool holder to analyze impact of the weakened structure onto the tool behavior. The cutting speed is set to $100 \mathrm{~m} /$ min with the depth of cut ae at $0.2 \mathrm{~mm}$. Carbide cutting
Fig. 3 Dimensions and position of the test specimens (units in $\mathrm{mm}$ )
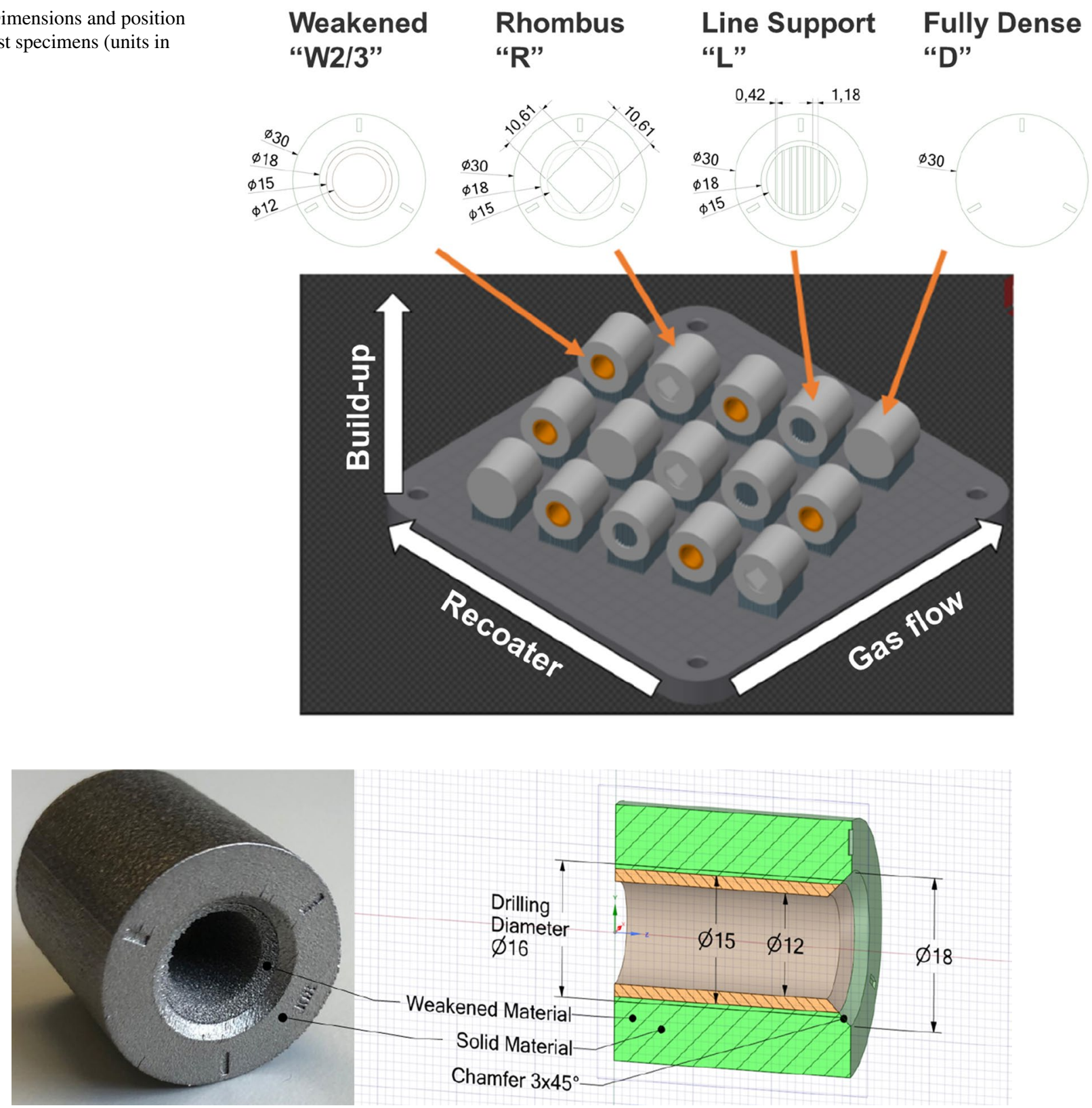

Fig. 4 Specimen with weakened structure W2 and section view of the bore (units in mm) 
Fig. 5 Test setup for the analysis of orthogonal cutting processes

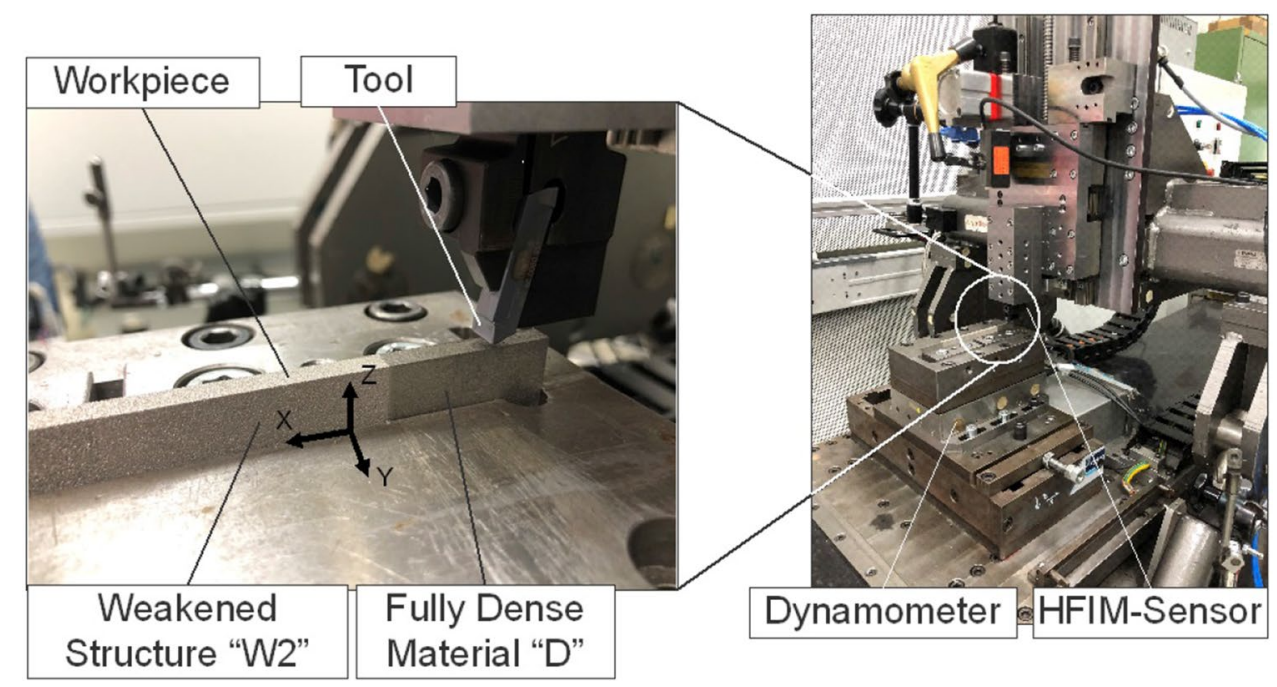

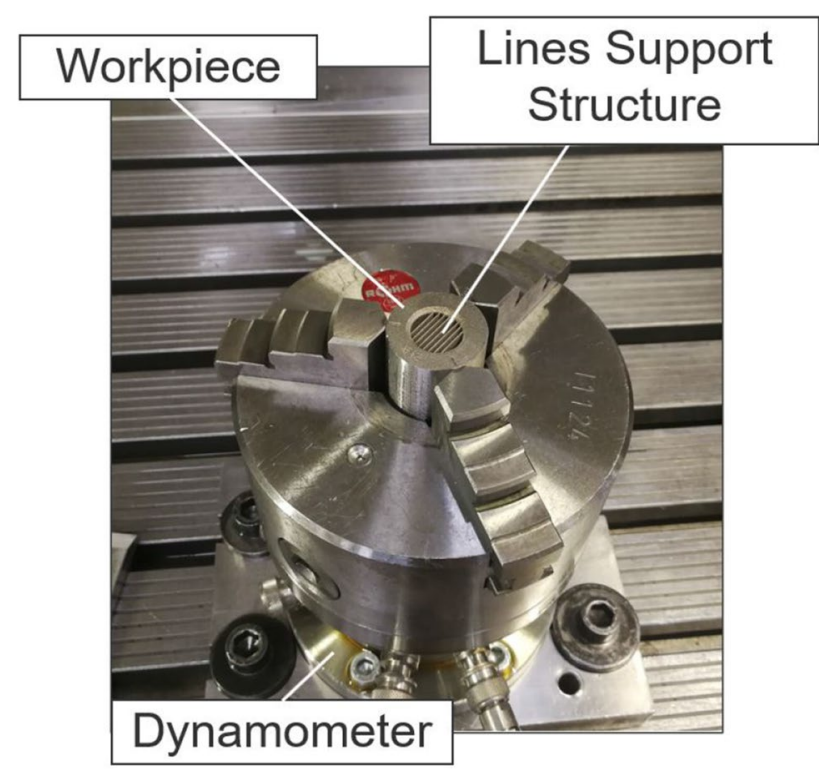

Fig. 6 Test setup for the drilling process

inserts with a proprietary TI25 coating by Paul Horn $\mathrm{GmbH}$ are used for the orthogonal cutting experiments.

Drilling experiments for the application samples are conducted with a Hermle UWF 1202 machining center with emulsion cooling. Process forces $F_{z}$ as well as the drilling moment $M_{z}$ about the rotational axis of the drill are measured during machining using a Kistler Charge Amplifier force plate type 9273 using the Workpiece coordinate system $\left(F_{x}, F_{y}, F_{z}\right)$ and the specimens are clamped on top with a three-jaw chuck. The test setup is shown in Fig. 6. A carbide drill with two cuttings edges, internal cooling, diameter of $15.8 \mathrm{~mm}$ and proprietary nanoFIRE coating from the company Gühring is used with a selected cutting speed of $v_{c}=$ $65 \mathrm{~m} / \mathrm{min}$ and feed of $\mathrm{f}=0.315 \mathrm{~mm} / \mathrm{U}$.
No intermediate process steps are carried out between the additive and subtractive processes. The weakened structure within the bores is completely cut away during machining, to guarantee a smooth surface without any remaining pores. To analyze and evaluate the resulting surfaces after drilling, roughness and cylindricity measurements are performed on all samples. Surface roughness of the machined inner bore wall is measured for each specimen on five lines along the bore axis using a surface measuring device Mitutoyo Surface Scanner SV-C3200. The cylindricity is measured using a CMM retrofitted by Renishaw with a REVO-2 5-axis system and RSP2 scanning head with RSH250-6x10 stylus.

\section{Orthogonal cutting results}

The experimental tests of orthogonal cutting are carried out with four individual sections. The four sections are made out of weakened structure W3, weakened structure W2 and dense base material respectively (Fig. 7).

During the cutting process the resulting forces are measured. Figure 7 presents the cutting force $F_{x}$ and the thrust force $F_{z}$ over time (sampling rate $\mathrm{f}=10 \mathrm{kHz}$ ). The average measurement uncertainty is $4 \%$ for the cutting force and 5\% for the thrust force. As can be inferred from the figures, the forces change through the four individual sections. Due to the pores intentionally made in the weakened structure, a clear reduction of the thrust force can be seen. This can be explained by the lower strength of the weakened structures. Figure 7 also shows the short time fourier transformation (STFT) of the structure-borne noise signal recorded with a sampling rate of $f=800 \mathrm{kHz}$ during the cutting process.

During the cutting process the weakened material has a higher plastic content due to the pores and can therefore compress more easily. This leads to better damping behavior 
Fig. 7 Structure borne noise signal and force signals during cutting

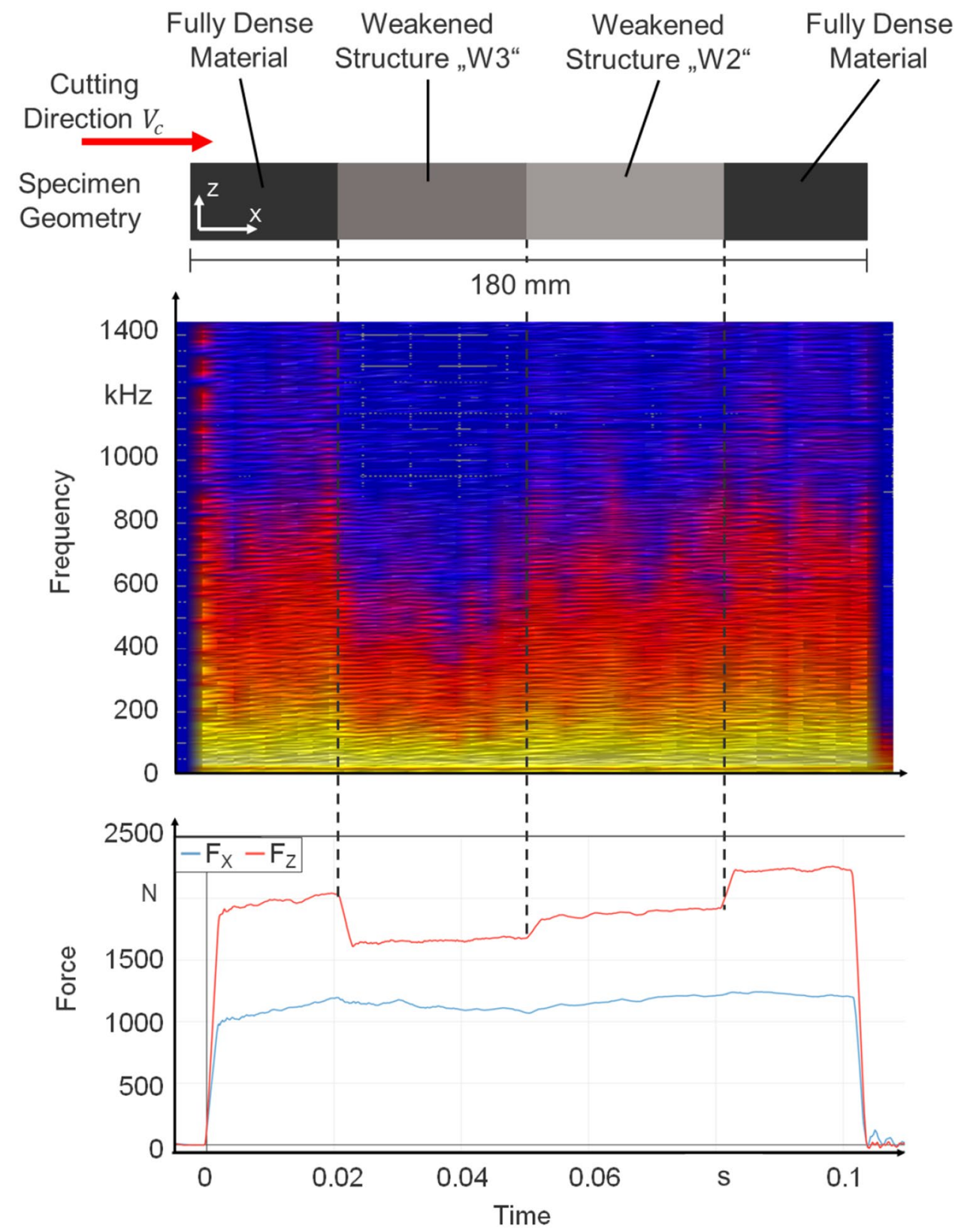

which can be seen in the structure-borne noise signal as well as in the force signal.

The different sections can also be distinguished in the chip formation. The weakened structure W3 can be seen on the surface and the edges of both chips (W3 and W2) display a decreased strength when comparing them to the chips formed from the fully dense section.

\section{Drilling results}

Drilling is selected to investigate the influence of the weakened structure on a more complex and practically relevant machining process. The cutting forces and chip formation during drilling as well as the resulting surface quality are examined in detail for this purpose.

\subsection{Cutting forces}

The median axial drilling force $F_{z}$ and the drilling moment $M_{z}$ as well as the respective median absolute deviation (MAD) during machining of samples without a prebuilt bore can be seen in Table 2 .

Listed are the conventionally manufactured steel samples, AM samples built with a fully dense material and the two investigated weakened structures. The difference between the additively produced solid samples and the reference steel samples is very small with $2.9 \%$ in force $F_{z}$ and $1 \%$ in 
Table 2 Median force $F_{z}$ and moment $M_{z}$ with respective MAD during drilling without prebuilt bore

\begin{tabular}{llllll}
\hline Samples & \multicolumn{2}{l}{ Force $F_{z}$} & & & Moment $M_{z}$ \\
\cline { 2 - 3 } \cline { 5 - 6 } \cline { 5 - 6 } & Median $(\mathrm{N})$ & MAD (N) & & Median $(\mathrm{Ncm})$ & MAD (Ncm) \\
\hline Reference & 5920 & 55 & & 3020 & 118 \\
AM solid & 5750 & 54 & & 2990 & 105 \\
AM W2 & 4850 & 49 & & 2650 & 74 \\
AM W3 & 3980 & 51 & & 2420 & 69 \\
\hline
\end{tabular}

moment $M_{z}$. The weakened structure samples on the other hand, deviate much more clearly. The measured force is reduced by $16 \%$ and $31 \%$ for $\mathrm{W} 2$ and $\mathrm{W} 3$ samples respectively compared to the AM solid samples. The reduction in drilling moment is measured to be $11 \%$ and $19 \%$ for $\mathrm{W} 2$ and W3 samples, respectively. In general, all machining forces of samples without a prebuilt bore are exceedingly high, leading to challenges in machining of finely detailed highly optimized parts.

The reduction in machining forces encountered with the weakened structure are even more prevalent when inspecting the results of samples with a prebuilt bore and different support structures. The "Lines" and "Rhombus" samples show widely fluctuating machining forces of over $\pm 50 \%$, due to their geometry. The "Ring" samples on the other hand only show fluctuations around $\pm 10 \%$. Figure 8 shows the axial drilling force $F_{z}$ and the drilling moment $M_{z}$ plotted over time when machining the different support structures. To better visualize the traces, they are uniformly smoothed using a Savitzky-Golay filter.

The varying geometry encountered with the rhombus or line supports is the cause of vibrations in the tool and workpiece with negative effects on tool wear, surface quality and part clamping.

The weakened samples with cylindrical bore geometry on the other hand provides a more uniform cutting cross-section with less vibrations impacting the process. Furthermore, the magnitude of the machining forces can be significantly reduced using the weakened structure. The force $F_{z}$ of samples with the same geometry, but different variants with fully dense, $\mathrm{W} 2$ and $\mathrm{W} 3$ structures is measured at $730 \mathrm{~N}, 440 \mathrm{~N}$ and $350 \mathrm{~N}$ respectively. The moment $M_{z}$ is reduced from $1060 \mathrm{Ncm}$ for fully dense samples, down to $900 \mathrm{Ncm}$ for W2 and $830 \mathrm{Ncm}$ for W3 samples.

\subsection{Chip formation and surface properties}

Due to the high toughness of 1.2709 , the chips during machining with a low degree of deformation are typical long and snarled ribbon chips [26, 27]. This characteristic is negatively affecting the chip removal while drilling out pre-build bores, and detrimental to the resulting surface quality [27]. The internal cooling of the utilized drilling tools improves the chip removal but can not fully mitigate this issue. Ribbon chips are also wrapped around the drill bit and have to be removed by hand after cutting is finished. Therefore, a secondary focus of this investigation for the application specimen is on the optimization of chip formation towards shorter break chips, in addition to reduced cutting forces.

These typical snarled ribbon chips can be clearly seen after processing the line support samples. The thin support structure bars are broken off and pushed in front of the drill and the remaining machining allowance is cut and produces ribbon chips. The broken off support bars also influence the chip flow and cutting behavior, leading to surface scoring with deep grooves as can be seen in Fig. 9. The median roughness depth across all line support samples is measured at $R_{z}=36.82 \mu \mathrm{m}$.

The rhombus geometry can still be identified in chips resulting from the rhombus samples (see Fig. 9). The varying geometry leads to highly fluctuating process forces, changes chip formation and results in helical chips instead of snarled ribbon chips. This reduces the volume occupied by the chips and improves chip removal from the bore. Compared to the line support samples, there are no deep groves visible on the surface and the median roughness depth is improved to $R_{z}=13.75 \mu \mathrm{m}$. The long helical chips are still detrimental to the process however. Furthermore, it can be seen that the fluctuating process forces are causing process instability, resulting in visible marks on the surface (see Fig. 9).

In comparison to the reference support structures, the samples with the developed weakened structure only form short spiral chips (see Fig. 9). Due to the unique sample design, only a very small volume of solid material is being cut, with the rest made out of weakened material. This leads to a segmentation of the chip, and consequently to chip breakage. Chip removal out of the bore and away from the tool and workpiece is significantly improved, which is reflected in the resulting surface quality as well as the overall process stability. Median roughness depth is measured at $R_{z-W 2}=9.78 \mu \mathrm{m}$ and $R_{z-W 3}=11.45 \mu \mathrm{m}$ for the weakened structures $\mathrm{W} 2$ and $\mathrm{W} 3$ respectively and no grooves or chatter marks are visible.

Due to the large amount of material to be cut, there is enough energy present to break the chips of the fully dense AM samples without a prebuilt bore, resulting in short spiral chips (see Fig. 9). This also leads to an acceptable surface finish with a median roughness depth of $R_{z}=11.08 \mu \mathrm{m}$. The conventionally manufactured reference samples show the same results.

The cylindricity measurements also show that machining conventional support structures can negatively affect the resulting surface. Due to fluctuating cutting conditions, the 
Fig. 8 Filtered machining forces $F_{z}$ and $M_{z}$ of different support and weakened structures during drilling
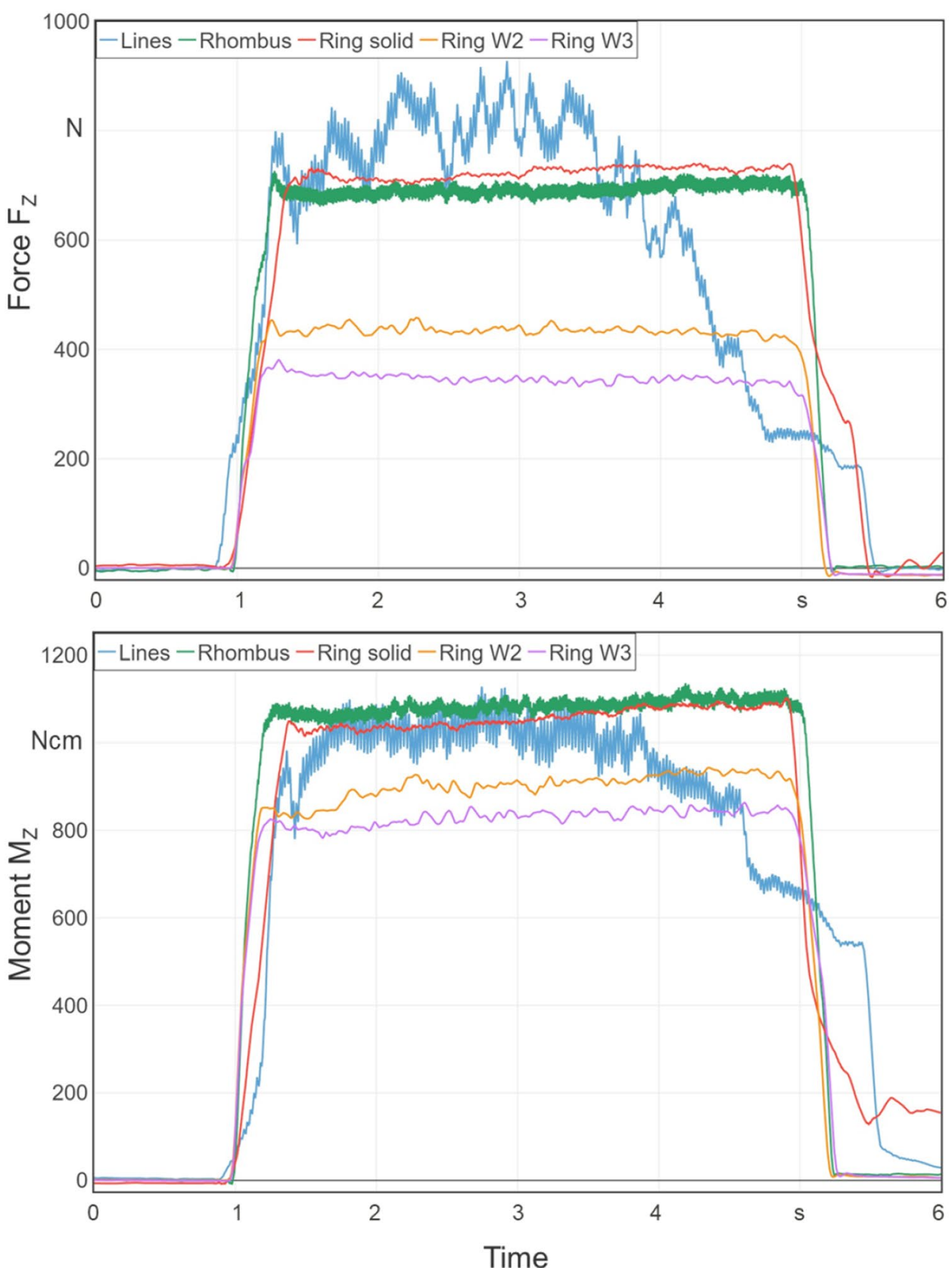

measured cylindricity of line and rhombus samples is higher than that of W2, W3 and fully dense samples (see Fig. 9).

\section{Conclussion and outlook}

The presented method makes it possible to adapt the material properties of the material that is to be removed in order to reduce the structural integrity and the encountered process forces. The method has the potential to significantly improve post-processing. The decisive advantage of the weakened structure, however, is the reduction in machining forces (for all machining processes with a defined cutting edge). So far, this effect has been proven in the drilling process and observed in tests. Further experiments, including turning and milling are currently pending.

The reduction in machining forces can be particularly beneficial for highly optimized and detailed components. These parts sometimes cannot withstand the high machining forces during post-processing and have to be strengthened, thus making machining forces the limiting factor and degrading possible performance gains from optimization. Using the presented method can mitigate this problem and enable the machining of high-end AM components. 


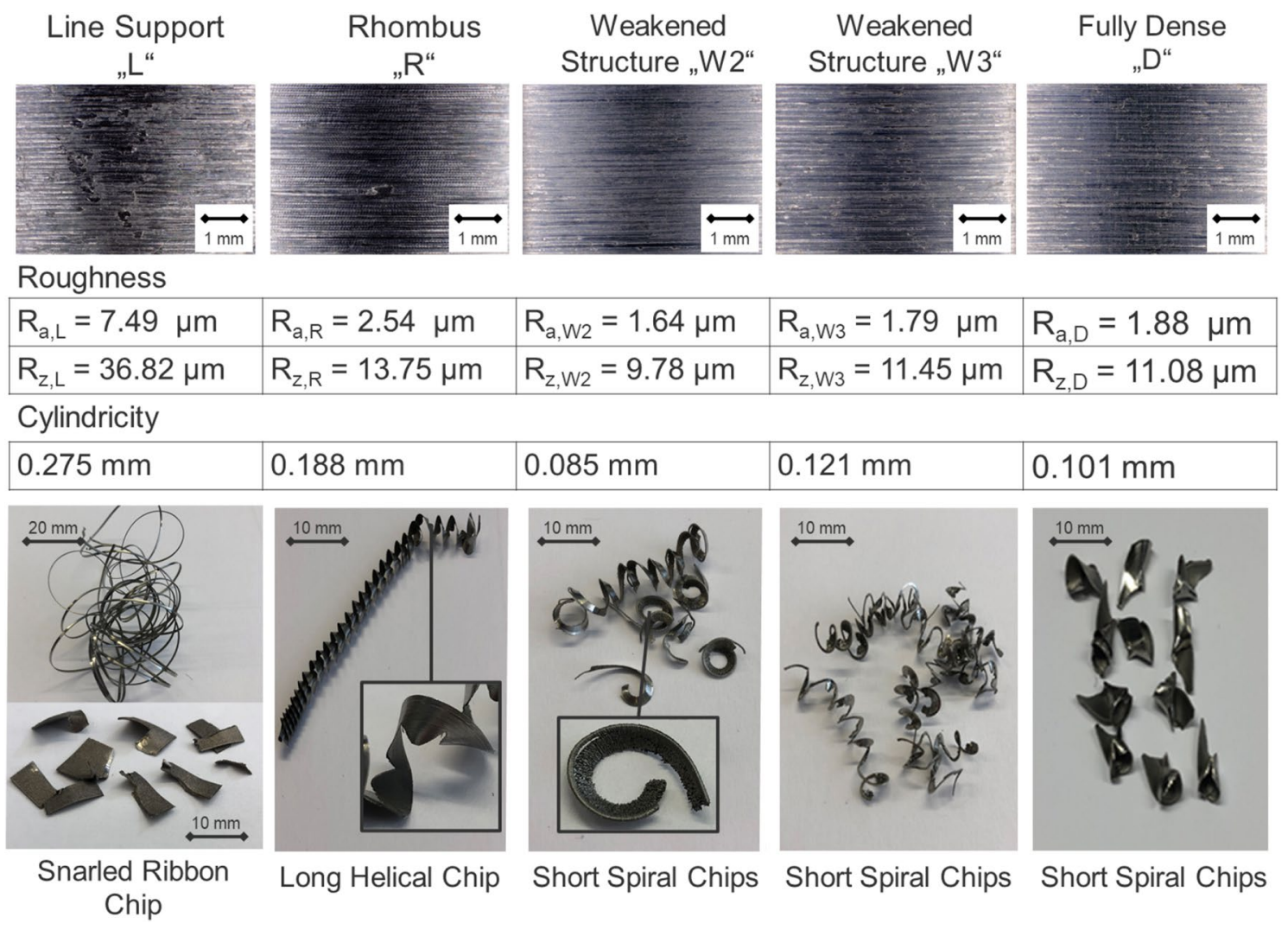

Fig. 9 Surface quality (median across total measured values) and chip formation of samples after drilling

In summary it can be said:

- The use of standard support structures for horizontal bores leads to challenges in chip removal and to reduced surface qualities.

- The chip formation and the process forces during drilling can be positively influenced by the weakened structure W2 in the LPBF process. The further weakened structure W3 led to a slightly worse surface quality.

- In general, good results can be achieved with regard to chip formation and surface quality through the use of weakened structures.

- Due to the reduced process forces during drilling, the clamping forces can also be reduced. With thin printed components this might solve a problem if the part cannot withstand the typically encountered forces during clamping.

- The lower and less fluctuating machining forces and vibrations are expected to lead to: easier clamping technology; less tool wear; shorter process times; higher surface qualities and higher cutting process stability because of better chip removal.

Even though the results so far are highly promising, further experiments are needed in order to gain a complete understanding of the complex interactions during the machining process of weakened structures, and how they affect the machining forces, chip formation and resulting surface finish. This understanding should begin with the simulation of the component during additive manufacturing and end with the process monitoring during machining. Currently ongoing efforts include further material characterizations, such as tensile tests and additional orthogonal cutting experiments. Other machining processes, such as milling and turning, as well as application examples for the weakened structure are planned to be investigated in the near future.

Acknowledgements This article was assisted with the kind contributions of Renishaw Deutschland GmbH, Gühring KG and Paul Horn $\mathrm{GmbH}$. Part of this work was supported by the German Federal Ministry for Economic Affairs and Energy by means of the research program Cornet/IGF during the research project Ad-Proc-Add.

Funding Open Access funding enabled and organized by Projekt DEAL.

Open Access This article is licensed under a Creative Commons Attribution 4.0 International License, which permits use, sharing, adaptation, distribution and reproduction in any medium or format, as long as you give appropriate credit to the original author(s) and the source, provide a link to the Creative Commons licence, and indicate if changes 
were made. The images or other third party material in this article are included in the article's Creative Commons licence, unless indicated otherwise in a credit line to the material. If material is not included in the article's Creative Commons licence and your intended use is not permitted by statutory regulation or exceeds the permitted use, you will need to obtain permission directly from the copyright holder. To view a copy of this licence, visit http://creativecommons.org/licenses/by/4.0/.

\section{References}

1. Thompson MK, Moroni G, Vaneker T, Fadel G, Campbell RI, Gibson I, Bernard A, Schulz J, Graf P, Ahuja B, Martina F (2016) Design for additive manufacturing: trends, opportunities, considerations, and constraints. CIRP Ann 65(2):737-760

2. Gao W, Zhang Y, Ramanujan D, Ramani K, Chen Y, Williams CB, Wang CCL, Shin YC, Zhang S, Zavattieri PD (2015) The status, challenges, and future of additive manufacturing in engineering. Comput Aided Des 69:65-89

3. Vaneker THJ (2017) The role of design for additive manufacturing in the successful economical introduction of AM. Proced CIRP 60:181-186

4. Chen T, Fritz S, Shea K (2015) Design for mass customization using additive manufacture: case-study of a balloon-powered car. In: Proceedings of the 20th international conference on engineering design (ICED15), Milan, Italy

5. Gebhardt A, Kessler J, Thurn L (2016) 3D-Drucken: Grundlagen und Anwendungen des Additive Manufacturing (AM). 2, neu bearbeitete und, erweiterte edn. Carl Hanser Verlag, München

6. Kranz J (2014) Design guidelines for laser additive manufacturing of lightweight structures in TiAl6V4. J Laser Appl 10(2351/1):4885235

7. Hashimoto F, Chaudhari RG, Melkote SN (2016) Characteristics and performance of surfaces created by various finishing methods. Proced CIRP 45:20

8. Ding D, Pan Z, Cuiuri D, Li H (2015) Wire-feed additive manufacturing of metal components: technologies, developments and future interests. Int J Adv Manuf Technol 81(1-4):465-481

9. Kumbhar NN, Mulay AV (2016) Post processing methods used to improve surface finish of products which are manufactured by additive manufacturing technologies: a review. The Institution of Engineers (India), Kolkata

10. Lin C, Fan Y, Zhang Z, Fu G, Cao X (2016) Additive manufacturing with secondary processing of curve-face gears. Int J Adv Manuf Technol 86:9-20

11. Papdakis L, Hauser C (2017) Experimental and computational appraisal of the shape accuracy of a thinwalled virole aero-engine casing manufactured by means of laser metal deposition. Prod Eng Res Devel 11:389-399

12. Dantan J-Y, Huang Z, Goka E, Homri L, Etienne A, Bonnet N, Rivette M (2017) Geometrical variations management for additive manufactured product. CIRP Ann Manuf Technol 66:161-164

13. Leach R, Bourell D, Carmignato S, Donmez M, Senin N, Dewulf W (2019) Geometrical metrology for metal additive manufacturing. CIRP Ann Manuf Technol. https://doi.org/10.1016/j. cirp.2019.05.004
14. Wei D, Bai Q, Zhang B (2016) A novel method for additive/subtractive hybrid manufacturing of metallic parts. Proced Manuf 5:1018-1030. https://doi.org/10.1016/j.promfg.2016.08.067

15. Iquebal A, Amri S, Shrestha S, Wang Z, Manogharan G, Bukkapatnam S (2017) Longitudinal milling and fine abrasive finishing operations to improve surface integrity of metal AM components. Proced Manuf 10:990-996. https://doi.org/10.1016/j.promf g.2017.07.090

16. Polishetty A, Shunmugavel M, Goldberg M, Littlefair G, Singh R (2017) Cutting force and surface finish analysis of machining additive manufactured titanium alloy Ti-6Al-4V. Proced Manuf 7:284-289. https://doi.org/10.1016/j.promfg.2016.12.071

17. Oyelola O, Crawforth Dr, M'Saoubi R, Clare A (2016) Machining of additively manufactured parts: implications for surface integrity

18. Hintze W, Schötz R, Mehnen J, Köttner L, Möller C (2018) Helical milling of bore holes in Ti6Al4V parts produced by selective laser melting with simultaneous support structure removal. Proced Manuf 18:89-96

19. Chatterjee AN (2003) An experimental design approach to selective laser sintering of low carbon steel. J Mater Process Technol 136(1-3):151-157

20. Van Bael SS, Chai YC, Truscello S, Moesen M, Kerckhofs G, Van Oosterwyck H, Kruth JP, Schrooten J (2012) The effect of pore geometry on the in vitro biological behavior of human periosteum-derived cells seeded on selective laser-melted Ti6Al4V bone scaffolds. Acta Biomater 8(7):2824-2834

21. Pyka G, Burakowski A, Kerckhofs G, Moesen M, Bael S, Schrooten J, Wevers M (2012) Surface modification of Ti6Al4V open porous structures produced by additive manufacturing. Adv Eng Mater 14:363-370. https://doi.org/10.1002/adem.201100344

22. Hazlehurst KB, Wang CJ, Stanford M (2014) An investigation into flexural characteristics of functionally graded cobalt-chrome femoral stems manufactured using selective-laser melting. Mater Des 60:177-183

23. Spierings A, Schoepf M, Kiesel R, Wegener K (2014) Optimization of SLM productivity by aligning 17-4PH material properties on part requirements. Rapid Prototyp J 20:444-448. https://doi. org/10.1108/RPJ-04-2013-0045

24. Spierings A, Herres N, Levy G (2011) Influence of the particle size distribution on surface quality and mechanical properties in AM steel parts. Rapid Prototyp J 17:195-202. https://doi. org/10.1108/13552541111124770

25. Louvis E, Fox P, Sutcliffe CJ (2011) Selective laser melting of aluminium components. J Mater Process Technol 211(2):275-284

26. CIRP (2014) CIRP encyclopedia of production engineering. https ://doi.org/10.1007/978-3-642-20617-7

27. Degner W, Lutze H, Smejkal E, Heisel U, Rothmund J (2019) Spanende Formung. https://doi.org/10.3139/9783446460638.fm

Publisher's Note Springer Nature remains neutral with regard to jurisdictional claims in published maps and institutional affiliations. 